\title{
A Clinic Investigation into Prehospital and Emergency Department Delays in Acute Stroke Care
}

\author{
Özcan Keskin ${ }^{a}$ Murat Kalemoğlu ${ }^{a}$ Rifat Eralp Ulusoy \\ ${ }^{a}$ Emergency and ${ }^{b}$ Cardiology Services, Gulhane Haydarpasa Military Teaching Hospital, Istanbul, Turkey
}

\section{Key Words}

Stroke $\cdot$ Acute stroke care $\cdot$ Emergency delay

\begin{abstract}
Objective: The aim of our study was to investigate the factors which cause prehospital and emergency department (ED) delays in acute stroke care. Subjects and Methods: We prospectively studied 229 acute stroke patients (median age: $71 \pm 19$ years, 90 female and 139 male) who presented to the ED of the Gulhane Military Teaching Hospital, Istanbul, Turkey. Prehospital delay was defined as time from symptom onset to arrival at the ED. Emergency delay was defined as time from initial examination in the ED to arrival at the Neurology Intensive Care Unit. Results: The median interval of prehospital and emergency delays were 92.66 and $53 \mathrm{~min}$, respectively. The major cause of the prehospital delay was the time from symptom onset to first call for medical help (68.21 $\mathrm{min}, 73.93 \%, \beta$ coefficients: $0.99 ; p<0.001$ ), and the major cause of the ED delay was waiting for the neurological consultation ( $21.28 \mathrm{~min}, 39.6 \%$ ), $\beta$ coefficients: $0.03 ; \mathrm{p}<0.001)$. Conclusion: The results indicate that prehospital and ED delays are due to late decision to seek medical care and delayed neurological consultation. Hence, educational campaigns are needed to increase public awareness of stroke signs and the necessity of
\end{abstract}

calling emergency services immediately when persons are suffering a possible stroke. Equally, ED physicians need to be trained in the recognition of symptoms and signs of acute stroke and the necessity for rapid neurological evaluation.

Copyright (C) 2005 S. Karger AG, Basel

\section{Introduction}

Stroke has been increasingly recognized as an important and expensive medical and social problem during the past 10 years [1-4]. Six years after approval of the use of intravenous recombinant tissue plasminogen activator for the treatment of patients with acute ischemic stroke in the United States, it was approved also in the European Union and in non-North American countries.

The maximum benefit for administering intravenous recombinant tissue plasminogen activator is within $3 \mathrm{~h}$ after stroke onset. Presentation after $3 \mathrm{~h}$ continues to be a primary cause of exclusion criteria for thrombolytic therapy in stroke patients in North America and may be a medical problem in areas recently using this therapy. Several studies have identified the factors which influence the delays in the treatment of acute stroke patients in different countries [2-10].

\section{KARGER}

Fax +4161306 1234 E-Mail karger@karger.ch www.karger.com
(C) 2005 S. Karger AG, Basel

1011-7571/05/0146-0408\$22.00/0

Accessible online at:

www.karger.com/mpp
Özcan Keskin, MD

Gulhane Haydarpasa Military Teaching Hospital

Department of Emergency, Selimiye Mah. Tibbiye Cad.

TR-34670 Uskudar/Istanbul (Turkey)

Tel. +90216542 2305, Fax +90216348 78880, E-Mail ozcan_keskin@hotmail.com 
Although the thrombolytic therapy was started in some of our university hospitals in 2004, the detailed investigation of the factors which cause delays in stroke intervention has not been carried out in Turkey. Therefore, the aim of this study was to investigate the factors causing prehospital and emergency department (ED) delays of acute stroke in the Istanbul metropolitan area.

\section{Subjects and Methods}

This prospective study was conducted between September 2003 and March 2004 in the ED of the Gulhane Military Teaching Hospital, Istanbul, Turkey, in patients with symptoms of stroke. A total of 229 (median age: $71.19 \pm 12.35$ years, 90 female) acute stroke patients were included in this study. Diagnosis of stroke was based on neurological examination that showed change in mental status, the weakness of the extremities, speech disturbance, paresthesia, vertigo and dizziness. The diagnosis was confirmed using computerized tomography (CT) to exclude neurological deficits other than stroke. The National Institutes of Health Stroke Scale (NIHSS) scoring system was used to assess the severity of stroke at admission (mild: 0-6, moderate: 7-15, severe: 16-38). The NIHSS cutoffs were prespecified, and the clinical judgment was based on previously reported suggestions [11-13].

The patients who died while being transported during the management in the ED were excluded from the study. The information regarding history, call for medical help and transportation time were obtained from the conscious patients, medical personnel or relatives of the unconscious patients.

Prehospital delay was defined as time from symptom onset to arrival at the ED. The delay was assessed as time interval between the medical call for help and transportation time. The call for medical help, which is assessed under the prehospital delay, was defined as time from the onset of symptoms to the decision to seek medical help. Time of symptom onset was defined as time when patients or bystanders noticed the symptoms. If symptoms occurred during sleep, the time of symptom onset was considered to be the time when the patient fell asleep. Patients who were admitted to the ED $48 \mathrm{~h}$ after onset of stroke symptoms were excluded from the study.

Emergency delay was defined as time from initial examination in the ED to arrival at the Neurological Intensive Care Unit. In this period we included the time it took for initial examinations, neurological consultation and $\mathrm{CT}$. The factors affecting this time delay were assessed by observational and prospective follow-up of each time period by writing down all events and delay time during the time intervals. The beginning of the emergency examination time was defined as the completion of the initial evaluation of the stroke patients by the ED doctor. The consultation time was defined as the completion of the neurological consultation, and the CT time as the completion of the CT. The patients diagnosed with acute ischemic stroke were transferred to the Neurological Intensive Care Unit, while those with hemorrhagic stroke were transferred to the Brain Surgical Intensive Care Unit.

The patients were divided into three groups according to the total delay time interval: group 1:<120 min; group 2: 120-300 min; group 3: $>301 \mathrm{~min}$.

Delays in Acute Stroke Care
The SPSS for Windows 10.0 pocket program was used for the statistical analysis. The continuous variables were analyzed by utilizing methods such as mean and standard deviation and frequency count, and percentage was utilized for the discontinuous variables. Kruskal-Wallis $\mathrm{H}$ analysis was utilized for the duo assessment of the groups. Multivariate linear regression (stepwise) analysis was utilized to explain the link between the time periods of the study with the total time. The dependent variables (age, sex, comorbidity, NIHSS, etc.), which affect the total intervention time of the stroke patients, were analyzed by logic log linear analysis. Statistical significance was set at $\mathrm{p}<0.05$.

\section{Results}

The demographic and clinical characteristics of the patients are given in table 1 . Of the 229 patients, 168 were conscious and 61 unconscious, as determined from the patients themselves, relatives or medical personnel. The most frequently noted symptoms in the conscious patients were limb weakness: $72 \%$, speech disturbance: $42 \%$, vertigo/dizziness: $21 \%$, sense defect/paresthesia: $20 \%$, facial paralysis: $4 \%$ and diplopia/loss of seeing: $4 \%$. Of the 61 unconscious patients, the most reported symptoms were loss of consciousness: $32 \%$, mental status change: $64 \%$, limb weakness: $59 \%$, speech disturbance: $34 \%$, convulsion: $8 \%$ and delirium: $5 \%$. For the unconscious patients, 7, 14 and 40 were in groups 1, 2 and 3, respectively.

The median NIHSS score at admission was 18. Eightyone patients $(35.3 \%)$ had a baseline NIHSS score above 25 . The causes of the stroke were considered as hemorrhagic in $19 \%$ and ischemic in $81 \%$. Sixty-three patients $(27.5 \%)$ had prior stroke. The clinical findings of the stroke patients are given in table 2. Seven of the patients died during the management in ED. Of the 7, 4 had hemorrhagic stroke and 3 ischemic stroke.

The median time of arrival to the ED for all patients was $92.66 \mathrm{~min}$. One hundred and thirteen patients (49\%) were examined in the ED within $3 \mathrm{~h}$ after symptom onset. The median time intervals from symptom onset to call for medical help were: group 1: $11.96 \mathrm{~min}$, group 2: $66.16 \mathrm{~min}$ and group 3: $126.28 \mathrm{~min}$. The time intervals of groups 2 and 3 were statistically significantly high ( $p<0.02$ to 0.0001 ) compared with the time interval of group 1.

The ambulance was used for the transfer of $179(77 \%)$ patients. The median transport times of the groups were $19.12,32.48$ and 24.30 min for groups 1, 2 and 3, respectively (table 3). It took longer to transport group 2 patients than group 1 or group 3 patients (table 3 ). The median 
Table 1. Demographic, social and clinical characteristics of the groups

\begin{tabular}{|c|c|c|c|c|}
\hline & $\begin{array}{l}\text { Group } 1 \\
\mathrm{n}(\%)\end{array}$ & $\begin{array}{l}\text { Group } 2 \\
\mathrm{n}(\%)\end{array}$ & $\begin{array}{l}\text { Group } 3 \\
\mathrm{n}(\%)\end{array}$ & $\mathrm{p}^{1}$ \\
\hline \multicolumn{5}{|l|}{ Age, years } \\
\hline$<65$ & $35(31)$ & $11(15.9)$ & $2(4.3)$ & \multirow[t]{2}{*}{$0.001^{*}$} \\
\hline$>65$ & $78(69)$ & $58(84.1)$ & $45(95.7)$ & \\
\hline \multicolumn{5}{|l|}{ Sex } \\
\hline Female & $68(60.2)$ & $45(65.2)$ & $26(55.3)$ & \multirow[t]{2}{*}{0.556} \\
\hline Male & $45(39.8)$ & $24(34.8)$ & $21(44.7)$ & \\
\hline \multicolumn{5}{|l|}{ Education } \\
\hline Less than junior high & $39(34.5)$ & $33(47.8)$ & $28(59.6)$ & \multirow[t]{2}{*}{$0.010^{*}$} \\
\hline More than junior high & $74(65.5)$ & $36(52.2)$ & $19(40.4)$ & \\
\hline \multicolumn{5}{|l|}{ Living alone } \\
\hline Yes & $22(19.5)$ & $14(20.3)$ & $5(10.6)$ & \multirow[t]{2}{*}{0.342} \\
\hline No & $91(80.5)$ & $55(79.7)$ & $42(89.4)$ & \\
\hline \multicolumn{5}{|l|}{ Comorbid diseases } \\
\hline Yes & $42(37.2)$ & $30(43.5)$ & $34(72.3)$ & \multirow[t]{2}{*}{$0.001 *$} \\
\hline No & $71(62.8)$ & $39(56.5)$ & $13(27.7)$ & \\
\hline \multicolumn{5}{|c|}{ Recognitions of symptoms by patients } \\
\hline Yes & $99(87.6)$ & $53(76.8)$ & $16(34)$ & \multirow[t]{2}{*}{$0.001 *$} \\
\hline No & $14(12.4)$ & $16(23.2)$ & $31(66)$ & \\
\hline \multicolumn{5}{|c|}{ Nocturnal onset (11 p.m.- 6 a.m.) } \\
\hline Yes & $30(26.5)$ & $36(52.2)$ & $27(57.4)$ & \multirow[t]{2}{*}{$0.001 *$} \\
\hline No & $83(73.5)$ & $33(47.8)$ & $20(42.6)$ & \\
\hline \multicolumn{5}{|l|}{ Arrival through referral } \\
\hline Yes & $35(31)$ & $17(24.6)$ & $15(31.9)$ & \multirow[t]{2}{*}{0.597} \\
\hline No & $78(69)$ & $52(75.4)$ & $32(68.1)$ & \\
\hline \multicolumn{5}{|l|}{ Arrival by EMS } \\
\hline Yes & $85(75.2)$ & $54(78.3)$ & $39(83)$ & \multirow[t]{2}{*}{0.557} \\
\hline No & $28(24.8)$ & $15(21.7)$ & $8(17)$ & \\
\hline $\begin{array}{l}* \mathrm{p}<0.05, \text { statistically } \\
{ }^{1} \chi^{2} \text { test. }\end{array}$ & & & & \\
\hline
\end{tabular}

Table 2. Stroke characteristics and NIHSS values of the patients

\begin{tabular}{lcccc}
\hline & $\begin{array}{c}\text { Group 1 } \\
\mathrm{n}(\%)\end{array}$ & $\begin{array}{c}\text { Group 2 } \\
\mathrm{n}(\%)\end{array}$ & $\begin{array}{c}\text { Group 3 } \\
\mathrm{n}(\%)\end{array}$ & $\mathrm{p}^{1}$ \\
\hline $\begin{array}{l}\text { Previous stroke } \\
\text { Yes }\end{array}$ & $20(17.7)$ & $15(21.7)$ & $28(59.6)$ & $0.001^{*}$ \\
No & $93(82.3)$ & $54(78.3)$ & $19(40.4)$ & \\
Ischemic stroke & & & & \\
Yes & $81(71.7)$ & $61(88.4)$ & $42(89.4)$ & $0.005^{*}$ \\
No & $32(28.3)$ & $8(11.6)$ & $5(10.6)$ & \\
NIHSS score at admission & & & \\
0-6 & $3(2.7)$ & $6(8.7)$ & $18(38.3)$ & $0.001^{*}$ \\
$7-24$ & $8(7.1)$ & $23(33.3)$ & $16(34)$ & \\
$16-25$ & $41(36.3)$ & $25(26.2)$ & $8(17)$ & \\
$26-38$ & $61(54)$ & $15(21.7)$ & $5(10.6)$ & \\
\hline
\end{tabular}

$* \mathrm{p}<0.05$, statistically significant.

${ }^{1} \chi^{2}$ test. times of initial examination in the ED for groups 1,2 and 3 were $10.7,14.54$ and $14.91 \mathrm{~min}$, respectively (table 3). The initial examination time for groups 2 and 3 was longer than for group 1 and the difference was statistically significant $(\mathrm{p}=0.0001)$. The median consultation times were 15.94, 24.1 and 25.09 min for groups 1, 2 and 3, respectively. The consultation time for group 3 was statistically significantly higher compared with groups 2 and 3 (table 3 ). Groups 2 and 3 showed higher CT times than group 1 (table 3 ). The effect of the study time intervals on total delay was assessed by multivariate linear (stepwise) regression analysis, and the time from symptom onset to first call for medical help was a strong indicator of total time delay ( $\beta$ coefficients: 0.99, $p<0.001$ ). But the other factors which affected the total time delay were consultation time in the ED ( $\beta$ coefficients: 0.03 , p < 0.001 ), transportation time ( $\beta$ coefficients: $0.03, p<$ 
Table 3. Comparison of the time interval differences in all groups

\begin{tabular}{lcrrr}
\hline Time interval, min & Group 1 & \multicolumn{1}{l}{ Group 2 } & \multicolumn{1}{l}{ Group 3 } & $\mathrm{p}^{1}$ \\
& & & & \\
\hline Time from symptoms to decision to seek medical help & $11.96 \pm 5.9$ & $66.16 \pm 57.84$ & $126.28 \pm 9.64$ & $0.001^{*}$ \\
Transport time & $19.12 \pm 7.11$ & $32.48 \pm 14.19$ & $24.3 \pm 5.62$ & $0.001^{*}$ \\
Time of emergency examination in ED & $10.7 \pm 4.15$ & $14.54 \pm 4.69$ & $14.91 \pm 5.06$ & $0.001^{*}$ \\
Time of consultations & $15.94 \pm 5.28$ & $24.1 \pm 18.18$ & $25.09 \pm 22.2$ & $0.001^{*}$ \\
Time of interpretation of CT & $18.97 \pm 6.97$ & $22.49 \pm 7.98$ & $24.91 \pm 9.17$ & $0.001^{*}$ \\
\hline
\end{tabular}

Values are expressed as median \pm standard deviation. ${ }^{*} \mathrm{p}<0.05$, statistically significant.

${ }^{1}$ Kruskal-Wallis $\mathrm{H}$ test.

$0.001)$ and CT time ( $\beta$ coefficients: $0.008, p<0.02)$. The initial examination time had no impact on the total time delay. Hence, the emergency examination time was excluded automatically by the statistical program during the statistical analysis. The most important factors which affected the total delay time in the prehospital period were call for medical help and consultation times in the ED (table 3).

The clinical and demographic outcomes which affected the total intervention time delay were advanced age (95\% CI: $0.01-0.09 ; p<0.01$ ), unawareness of symptoms (95\% CI: $1.38-2.86 ; \mathrm{p}<0.001)$, prior stroke $(95 \% \mathrm{CI}$ : -1.48 to $-0.08, \mathrm{p}<0.03$ ), comorbidity (95\% CI: $0.54-$ $1.81 ; \mathrm{p}<0.001)$ and low NIHSS score $(95 \% \mathrm{CI}:-0.19$ to $-0.11 ; \mathrm{p}<0.001)$.

\section{Discussion}

Our study indicated that the major cause of the prehospital delay was the time from symptom onset to first call for medical help (median $68.21 \mathrm{~min}$ ). This finding is consistent with other reports, and is related particularly to patients 65 years of age or more [3, 4, 13-19]. The probable explanation is that these patients are less likely to know the symptoms of stroke than the younger ones, as reported by Harraf et al. [9].

The other important factor which affected the delay for medical help was the consciousness of the patient, particularly if compounded by prior stroke and chronic neurological diseases such as dementia, Alzheimer's disease, advanced heart and respiratory failure $[13,14]$. In the present study, $59.6 \%$ of patients had suffered previous stroke and $72.3 \%$ had comorbidity leading to a total delay time of over $301 \mathrm{~min}$, similar to previous study.
Patients experiencing severe stroke, as measured by NIHSS score at admission, respond more quickly than patients with less severe stroke. This finding implies that the perceived urgent nature of the illness might be a factor contributing to decreased prehospital delay, as reported previously $[17,18]$ and in the present study where NIHSS score was $\geq 25$.

In many studies it has been shown that the use of Emergency Medical System (EMS) can shorten prehospital delay $[3,4,6,7,12,15]$. Chang et al. [14] reported that in Taiwan the mean transportation time from the location of onset or the first visited medical facilities to the study hospital was $30 \mathrm{~min}$. In the present study where a total of $85(37 \%)$ patients used the EMS, the mean transportation time to the first contacted medical facility was $24.21 \mathrm{~min}$. The prehospital delay was not affected by the use of EMS. But if the patients arrived through a referral hospital (67\%), prehospital delay was significantly increased. Our findings were similar to previous studies in this regard $[3,4,6,14,15]$.

The National Institute of Neurological Disorders and Stroke (NINDS) developed recommendations for the care of patients presenting with signs and symptoms of acute ischemic stroke. The recommendations are evaluation by emergency physician in less than $10 \mathrm{~min}$, interpretation of CT scans within $45 \mathrm{~min}$, and administration of tPA within $1 \mathrm{~h}$ after presentation [16]. In this study there was a delay of $1 \mathrm{~h}$ and $13 \mathrm{~min}$ for the initial emergency neurologic evaluation. Similar to the NINDS recommendation, CT scan took $20.25 \mathrm{~min}$, consultation time in the ED was $21.28 \mathrm{~min}$. These findings demonstrate the need for training medical personnel in the recognition of symptoms and signs of acute stroke in the ED and the necessity of rapid neurological consultation $[5,6]$. 


\section{Conclusion}

The results indicate that prehospital and ED delays are due to late decision to seek medical care and delayed neurological consultation. Hence, educational campaigns are needed to increase public awareness of stroke signs and the necessity of calling emergency systems immediately when persons are suffering a possible stroke. Equally important, ED physicians should be trained in the recognition of symptoms and signs of acute stroke and the necessity for rapid neurological evaluation.

\section{References}

1 Mitka M: Tensions remain over tPA for stroke. JAMA 2003;289:1363-1364.

2 Evenson KR, Rosamond WD, Morris DL: Prehospital and in-hospital delays in acute stroke care. Neuroepidemiology 2001;20:65-76.

3 Morris DL, Rosamond W, Madden K, Schultz C, Hamilton S: Prehospital and emergency department delays after acute stroke: the Genentech Stroke Presentation Survey. Stroke 2000; 31:2585-2590.

-4 Nedeltchev K, Arnold M, Brekenfeld C, Isenegger J, Remonda L, Schroth G, Mattle HP: Pre- and in-hospital delays from stroke onset to intra-arterial thrombolysis. Stroke 2003;34: 1230-1234.

-5 Menon SC, Pandey DK, Morgenstern LB: Critical factors determining access to acute stroke care. Neurology 1998;51:427-432.

-6 Kothari R, Jauch E, Broderick J, Brott T, Sauerbeck L, Khoury J, Liu T: Acute stroke delays to presentation and emergency department evaluation. Ann Emerg Med 1999;33:3-8.

-7 Lin CS, Tsai J, Woo P, Chang H: Prehospital delay and emergency department management of ischemic stroke patients in Taiwan, R.O.C. Prehosp Emerg Care 1999:3:194-200.
Lacy C, Suh D, Bueno M, Kostis J, for the STROKE Collaborative Study Group: Delay in presentation and evaluation for acute stroke: Stroke Time Registry for Outcomes Knowledge and Epidemiology (STROKE). Stroke 2001;32:63-69.

-9 Harraf F, Sharma AK, Brown M, Lees KR, Vass RI, Kalra L: A multicentre observational study of presentation and assessment of acute stroke. BMJ 2002:325;17-20.

10 Yu RF, San Jose MC, Manzanilla BM, Oris MY, Gan R: Sources and reasons for delays in the care of acute stroke patients. J Neurol Sci 2002;199:49-54.

-11 Adams HP Jr, Davis PH, Leira EC, Chang KC, Bendixen BH, Clarke WR, Woolson RF, Hansen MD: Baseline NIH Stroke Scale score strongly predicts outcome after stroke: a report of the Trial of Org 10172 in Acute Stroke Treatment (TOAST). Neurology 1999;53:126-131.

12 DeGraba TJ, Hallenbeck JM, Pettigrew KD, Dutka AJ, Kelly BJ: Progression in acute stroke: value of the initial NIH Stroke Scale score on patient stratification in future trials Stroke 1999;30:1208-1212.

13 Tan TY, Chang KC, Liou CW: Factors delaying hospital arrival after acute stroke in southern Taiwan. Chang Gung Med J 2002;25:458463.
14 Chang KC, Tseng MC, Tan TY: Prehospital delay after acute stroke in Kaohsiung, Taiwan. Stroke 2004;35:700-704.

15 Leopoldino JF, Fukujima MM, Silva GS, do Prado GF: Time of presentation of stroke patients in São Paulo Hospital. Arq Neuro Psiquiatr 2003;61:186-189.

16 Stahl JE, Furie KL, Gleason S, Gazelle GS: Stroke: Effect of implementing an evaluation and treatment protocol compliant with NINDS recommendations. Radiology 2003;228:659688.

17 Derex L, Adeleine P, Nighoghossian N, Honnorat J, Trouillas P: Factors influencing early admission in a French stroke unit. Stroke 2002; 33:153-159.

18 Wester P, Radberg J, Lundgren B, Peltonen M, for the Seek Medical Attention in Time Study Group: Factors associated with delayed admission to hospital and in-hospital delays in acute stroke and TIA: a prospective, multicenter study. Stroke 1999;930:40-48.

19 Kothari R, Sauerbeck L, Jauch E, Broderick J, Brott T, Khoury J, Liu T: Patients' awareness of stroke signs, symptoms, and risk factors. Stroke 1997;28:1871-1875. 